\title{
Some notes on the use of hygrograms for phytopathological purposes with special reference to their reliability
}

\author{
G. A. DE WEILLE \\ Royal Netherlands Meteorological Institute (K.N.M.I.), De Bilt
}

\begin{abstract}
Summary
Measurements of relative humidity (r.h.) in standard meteorological screens mounted at the conventional height do not provide a decisive measure for momentary values of the atmospheric humidity in a crop. It is not possible to infer such values from simultaneous screen data. For several phytopathological purposes it is therefore necessary to measure the r.h. in the crop.

Hygrographs are suited to the measurement of humidities exceeding $90 \%$, provided a special method of reading the hygrometric charts is adhered to.
\end{abstract}

Statistical evidence is adduced.

\section{Introduction}

Conidiophores and conidia of several phytopathogenic fungi are only formed in a saturated or nearly satured atmosphere. Moreover the humidity of the air is considered to be the main factor governing the longevity of these conidia (see e.g. Crosier, 1934, with regard to Phythophthora infestans).

Hence atmospheric humidity gained a predominant place in epidemiological thinking, in particular as far as potato blight and related diseases are concerned. This finds expression in the majority of the 'rules' applied in blight warning systems. In such rules a humidity criterion is usually combined with a temperature criterion. Crop infection is assumed in case the critical conditions thus indicated have prevailed during a specified minimum period (for examples see BouRKE, 1955).

\section{Expression of atmospheric humidity}

The units in which the air-humidity factor is expressed are usually percentages of relative humidity (\% r.h.).

Post (1957) made use of the concept 'dew point difference' (d.p.d.). This is the difference between the actual temperature $T$ and the dew point $T_{d}$ measured simultaneously; $T-T_{d}=$ d.p.d. PosT used d.p.d.'s because he made use of synoptic humidity data, which are teletyped in the form of dew-point measurements.

It should be borne in mind that the quantity r.h. is almost meaningless without statement of the temperature. In his work on potato blight epidemiology the author (1964a) therefore prefers the quantity s.d., i.e. the saturation deficit, for its being

Received for publication 20th February, 1964.

Neth. J. agric. Sci., Vol. 12 (1964) No. 3 (August) 
somewhat more conservative than the quantity r.h. (for definitions see PENMAN, 1955). Within a modest temperature range, for instance that in a potato crop during the night, the s.d. can be treated as a quantity independent of $T$.

The use of s.d. was already advocated by Srevens (1916) and Livingston (1917). The latter pointed out that the r.h. is not a satisfactory unit of comparison whenever more than one $T$ is employed, whereas - within certain limits - the s.d. demands no correction for $T$.

The influence of $T$ is included in the s.d. since the maximum vapour pressure depends on it. Stevens (1916) stated that the rate of evaporation is more proportional to the s.d. than to the r.h. Meanwhile it should always be remembered in this connection that differences in $T$ as such may also be significant for a plant, so that the use of the s.d. advocated here should not result in neglecting $T$.

\section{Height of observation}

Several research workers are concerned about the unnatural environment created in climatic chambers. The view is sometimes encountered that laboratory results obtained with fungi may not hold good under natural crop conditions. Departures from field conditions are held responsible for misleading laboratory results when field results do not fall into line with previously obtained laboratory data.

The responses of fungi to environmental factors, however, are innate properties of a general validity. The author therefore takes the view that, where the difficulties already mentioned are met, neither the fungus nor the laboratory is at fault, but that usually the measurement of physical variables in the field has to be faulted.

Laboratory and field observations made in so-called correlative studies should be of comparable accuracy (DE WEILLE, 1963, 1964b) in that they reflect equally well the physical environment of the fungus.

In this connection the height of observation in the field is very important. If r.h. is measured in a standard meteorological screen $1,50 \mathrm{~m}$ off the ground, it is a fallacy to suppose that to a fungus this humidity has the same meaning as the r.h. as measured in the laboratory. These two measurements are not comparable. It is therefore necessary to measure the r.h. in the crop close to the foliage in order to measure in the real ecoclimatic environment of the fungus.

In phytopathological field investigations the height of air-humidity observation varies. In the practical operation of blight warning systems there is a tendency to conform with the practices of the synoptic network, namely measurement in a standard meteorological screen at $1,50 \mathrm{~m}$ above ground (formerly $2 \mathrm{~m}$ above ground).

For his potato blight warning system VAN EVERDINGEN (1926) introduced measurements at a height of $40 \mathrm{~cm}$ in an otherwise normal screen. BEAUMONT (1947) measured r.h. in a screen placed at ground level among the potato plants. Meanwhile the screen still constitutes an unnatural element.

For measuring the humidity in the crop the hygrographs (or other measuring instruments) should be placed in that crop, e.g. on the ground between two rows of plants.

Over the years attempts have been made to transform screen data into (ecoclimatological) crop data, preferably by means of a single term. For the purpose of warnings against downy mildew in onions (Peronospora destructor), VAN DooRN (1959) compared r.h.-measurements at $10 \mathrm{~cm}$ and at $2,20 \mathrm{~m}$, finding that the difference amounted to about $5 \%$. UhLIG (1957) stated that if an r.h. of $95 \%$ is to prevail in a potato crop, an r.h. of $88 \%$ or a d.p.d. $\leqslant 2{ }^{\circ} \mathrm{C}$ has to be measured in the screen. 
Post and RICHEL (1951) found that on an average the 24-hour mean of r.h. measured at a height of $40 \mathrm{~cm}$ (in a screen; $c f$. VAN EVERDINGEN, 1926) exceeds that observed at $2,20 \mathrm{~m}$ by about $3 \%$.

HIRST (1958) compared measurements of r.h. in a potato crop, level with the tops of the ridges, with r.h. data obtained in a standard louvred screen, $1,50 \mathrm{~m}$ off the ground and found that during the season the relationship between the two sets of humidity data is gradually modified by the development of the plants ( $c f$. DE WEILLE, 1964 a).

The findings of HIRsT (1958), verified by the author, show that there is no justification for transforming screen data into crop data.

Uhlig (1957), Post and Richel (1951) and van Doorn (1959) all come to their conclusions by making use of data averaged in some way or other. Unfortunately enough, such averaged data are not valid for the actual momentary situation which often contradicts the relations existing between means of r.h.

The physical meaning of an averaged r.h. is more than doubtful; in principle the biological significance is also contested by the author (1964 a) who found, for instance, that more or less momentary values of the s.d. are decisive for the development of potato blight inoculum. Significant sporulation is closely linked with the nocturnal incidence in the crop of a very low saturation deficit. There is no such close relationship with the analogous screen data (DE WeILle, 1964 a).

The occurrence of a low s.d. (or a high r.h.) in the crop is not very consistently related with the simultaneous, previous or later occurrence of a corresponding level of humidity outside the crop, nor does an increase or decrease of the air humidity in the crop consistently correspond to a simultaneous or systematically earlier or later increase or decrease of the humidity measured in the screen, so that screen data are no decisive measure for biological processes in the crop.

\section{Hygrographs}

In the author's blight research use is made of hygrographs. These instruments are often used without the know-how required. Some non-meteorologists may use them for years without adjustment, whereas in meteorological circles the inexactitude of hygrograph recordings, also called hygrometric charts or hygrograms, is almost proverbial.

The latter view conflicts with the fact that, in the author's field research, statistically reliable parasite/humidity relationships were established with the help of s.d.-values computed from hygrograms. Only low values of s.d., i.e. high r.h.-values, were considered in spite of the criticism encountered that hygrograms are extremely unreliable, especially in the region above $90 \%$, a view attributable to misapprehension of a statement made by BLEEKER (1942).

This physicist had noticed that a hygrograph indication of $100 \%$ will slowly fall, in the laboratory and in a constantly saturated atmosphere, until an ultimate (printed) level of $96 \%$ is finally reached. This statement, however correct, does not imply that errors of $4 \%$ or more are invariable made in the crop. Nor does it imply that the errors are greatest above $90 \%$ r.h.

If a method of reading especially suited to r.h.-values exceeding $90 \%$ is applied, much of the proverbial inaccuracy of hygrograms can be obviated.

The long horizontal parts in the hygrogram depict saturation of the ambient air. When these trajects are very long they will slant down slightly to a level on which the 
printed lines on the chart indicate a value between 95 and $100 \%$. Whether slanting or not, the whole of the nearly straight line recorded represents an r.h. of $100 \%$.

This implies that, when a gradual rise or a similar fall from the level of saturation is indicated, the nearest point of the straight traject should be used as the $100 \%$ standard level for adjusting the adjacent lower values inasmuch as values $\geqslant 90 \%$ are involved. Working in this way gave rise to significant results.

Two features must be mentioned in defence of the use of (good) hygrographs for phytopathological purposes.

a. Their reactions to the environment are slow. The instrument will not respond instantly to an r.h. quickly lowered in the laboratory. In the crop, the humidity regime does not show too rapid variations, so that, as long as high humidities are involved, a good hygrograph will not be too far from the truth.

An observer will not immediately affect the hygrogram just by his disturbing the ecoclimate because of the advantage that a hygrograph indicates, as it were, the humidity regime of, say, the last 10 minutes.

b. Since hygrographs are only ventilated naturally they record the situation just around the hair bundle. They may record the bundle's own surface wetness. This also applies to unventilated psychrometers mounted in the crop, whose dry bulb might sometimes be dimmed in spite of the plastic roof above it. Such instruments might represent the situation near a leaf surface, or its wetness, better than an Assmann psychrometer (ventilated by an artificial air current not normally prevalent in the crop), which only measures the humidity within a certain mass of air around the plants, partly under and maybe partly above the foliage canopy.

The two above arguments together with the use of s.d. instead of r.h. may be sufficient explanation of the mathematically significant nature of some responses of Phytophthora infestans and Peronospora destructor to air humidity determined with the help of values derived from hygrograms.

\section{Reliability tests}

Since certain critics doubted the validity of some of the author's experimental results (because the saturation deficits employed had been obtained from hygrograms), a mathematical test was applied in order to check the reliability of such data.

TABLE 1 refers to measurements by Post $(1957,1959)$ in potato crop; in 1956 and 1957 he had used Richard and Fuess hygrographs (with weekly rotation) in conjunction with (unventilated) dry- and wet-bulb thermometers. TABLE 2 refers to more recent measurements in a $\times$ Rhododendron hybridum bush.

Starting from the hypothesis that the psychrometer indications are correct, frequencydistribution tables were composed of the departures $u=r . h_{\text {.p(syschr. })}-r . h_{\text {.h(ygrogr.) }}$. This was done for different humidity regions of the hygrometric charts. The frequency tables showed that hygrograph recordings lose steadily in accuracy as the humidity region becomes lower.

In the TABLES 1 and 2 the computed mean deviations $\overline{\mathrm{u}}$ from psychrometrically obtained r.h.-values are given together with their standard deviation $s_{u}^{-}$; here $\overline{\text { r.h.h }} \cdot=$ $\overline{\mathrm{r} . h}_{\mathrm{p}}+\overline{\mathrm{u}} \pm \mathrm{s}_{\overline{\mathrm{u}}}$. The greater differences $(\overline{\mathrm{u}})$ are statistically significant: $\overline{\mathbf{u}}>3 \mathrm{~s}_{\overline{\mathrm{u}}}$. All r.h.h -data on which the tables are based were obtained by applying the technique of interpreting hygrograms described on pp. 231 (bottom) and 232 (top). 
TABLE 1. Mean departures $\overline{\mathrm{u}}$ of hygrograph readings in a number of humidity regions from corresponding dry- and wet-bulb data and their standard deviations $s_{\bar{u}}^{-}$. Data apply to measurements in potato crop; $n=$ number of observations per region of r.h.

\begin{tabular}{|c|c|c|c|c|c|c|c|}
\hline \multirow{3}{*}{$\begin{array}{r}\text { Range of } \\
\text { r.h.h in } \%\end{array}$} & \multicolumn{3}{|c|}{ RICHARD (1956) } & \multicolumn{3}{|c|}{ FUESS (1957) } & \\
\hline & \multicolumn{3}{|c|}{$\overline{\mathrm{r} \cdot \mathrm{h}_{\mathrm{h}}}=\overline{\mathrm{r} \cdot \bar{h}_{\mathrm{p}}}+\overline{\mathrm{u}} \pm \mathrm{s} \overline{\mathrm{u}}$} & \multicolumn{3}{|c|}{${\bar{r} \cdot \bar{h}_{h h}}={\bar{r} \cdot \bar{h}_{\cdot p}}+\bar{u} \pm s \bar{u}$} & \\
\hline & $\mathbf{n}$ & $\overline{\mathbf{u}}$ & $\mathrm{s}_{\mathrm{u}}^{-}$ & $\mathbf{n}$ & $\overline{\mathrm{u}}$ & $\mathrm{s}_{\mathrm{u}}^{-}$ & \\
\hline $96-100$ & 24 & $+0,04$ & $\pm 0,13$ & 15 & $+0,40$ & $\pm 0,17$ & r.h.h $=$ rel. humidity as \\
\hline $87-95$ & 24 & $-1,08$ & $\pm 0,33$ & 18 & $+0,17$ & $\pm 0,63$ & indicated by hygrograph. \\
\hline $79-86$ & 25 & $-2,80$ & $\pm 0,50$ & 17 & $-3,24$ & $\pm 0,65$ & r.h.p $=$ r.h. as computed \\
\hline $70-78$ & 24 & $-2,50$ & $\pm 0,18$ & 25 & $-5,56$ & $\pm 0,77$ & from unventilated psy- \\
\hline$<70$ & 6 & $(-2,17)$ & $( \pm 0,72)$ & 39 & $-8,26$ & $\pm 0,83$ & chrometer readings. \\
\hline
\end{tabular}

TABLE 2. As table 1, but referring to measurements in a rhododendron bush

\begin{tabular}{|c|c|c|c|c|c|c|c|c|c|}
\hline \multirow{3}{*}{$\begin{array}{l}\text { Range of } \\
\text { r.h.h in } \%\end{array}$} & \multicolumn{3}{|c|}{ RICHARD (1963) } & \multicolumn{3}{|c|}{ FUESS (1963) } & \multicolumn{3}{|c|}{ FUESS (1963; daily rotation) } \\
\hline & \multicolumn{3}{|c|}{ 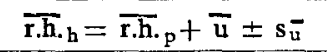 } & \multicolumn{3}{|c|}{$\bar{r} \cdot h \cdot h_{h}=\bar{r} \cdot h_{p}+\bar{u} \pm s_{u}$} & \multicolumn{3}{|c|}{$\bar{r} \cdot \bar{h}_{\cdot h}={\bar{r} \cdot h_{\cdot p}}_{p}+\bar{u} \pm s \bar{u}$} \\
\hline & $\mathbf{n}$ & $\overline{\mathbf{u}}$ & $\mathbf{s}_{\mathrm{u}}^{-}$ & $n$ & $\overline{\mathbf{u}}$ & $\mathrm{s}_{\mathrm{u}}^{-}$ & $\mathrm{n}$ & $\overline{\mathbf{u}}$ & $\mathrm{s}_{\mathrm{u}}^{-}$ \\
\hline 96-100 & 37 & $-0,14$ & $\pm 0,15$ & 37 & $+0,32$ & $\pm 0,11$ & 39 & $+0,33$ & $\pm 0,14$ \\
\hline $87-95$ & 11 & $-0,18$ & $\pm 0,3$ & 15 & $+0,87$ & & 14 & & $\pm 0,34$ \\
\hline $75-86$ & 14 & $-2,21$ & $\pm 0,98$ & 15 & $-1,73$ & $\pm 1,70$ & 14 & $+0,14$ & $\pm 0,95$ \\
\hline$<75$ & 7 & $-4,33$ & $\pm 1,17$ & 7 & $+0,29$ & $\pm 1,44$ & 6 & $+0,67$ & $\pm 2,04$ \\
\hline
\end{tabular}

The standard deviation of a single observation is simply s $\sqrt{n}$, where $n$ is the number of observations in the sample. In the humidity region $\geqslant 90 \%$ r.h. the author found s $\sqrt{\mathrm{n}} \leqslant 1 \%$ r.h., while in the range $75-85 \%$ r.h. $\mathrm{s} \sqrt{\mathrm{n}}$ appeared to amount to $>$ $3,5 \%$ r.h.

We may therefore conclude that well-adjusted and well-read hygrographs are reasonably useful for the registration of near-saturation, a mycologically very important condition.

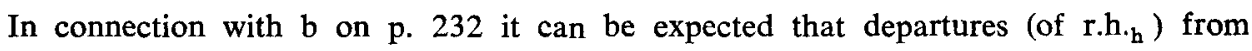
Assmann psychrometer readings r.h..$_{\mathrm{a}}$ exceed those from r.h.p .

TABLE 3 shows that this assumption is correct. Values of $s$ pertinent to $\bar{u}$ surpass corresponding data given in TABLE 2 .

TABLE 3. Mean departures $\overline{\mathrm{u}}$ of hygrograph readings from corresponding Assmann data and their standard deviations $\mathrm{s}_{\mathrm{u}}^{-}$. Measurements in a rhododendron bush

\begin{tabular}{|c|c|c|c|c|c|c|c|c|c|}
\hline \multirow{3}{*}{$\begin{array}{r}\text { Range of } \\
\text { r.h.h in \% }\end{array}$} & \multicolumn{3}{|c|}{ RICHARD (1963) } & \multicolumn{3}{|c|}{ FUESS (1963) } & \multicolumn{3}{|c|}{ FUESS (1963; daily rotation) } \\
\hline & \multicolumn{3}{|c|}{ 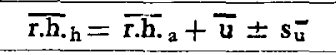 } & \multicolumn{3}{|c|}{$\bar{r}_{h} \cdot h={\bar{r} \cdot h_{\cdot a}}+\bar{u} \pm s_{u}$} & \multicolumn{3}{|c|}{${\bar{r} \cdot h_{h}}_{h}={\bar{r} \cdot h_{\cdot a}}+\bar{u} \pm s_{u}$} \\
\hline & $\mathrm{n}$ & $\overline{\mathbf{u}}$ & $\overrightarrow{\mathbf{u}_{\mathrm{u}}}$ & $\mathrm{n}$ & $\overline{\mathrm{u}}$ & $\mathrm{s}_{\mathrm{u}}^{\overline{-}}$ & $\mathrm{n}$ & $\overrightarrow{\mathbf{u}}$ & $\mathrm{s}_{\mathrm{u}}$ \\
\hline $\begin{array}{l}96-100 \\
87-95 \\
75-86\end{array}$ & $\begin{array}{r}15 \\
4 \\
4\end{array}$ & $\begin{array}{r}+1,20 \\
+0,50 \\
-3,50\end{array}$ & $\begin{array}{l} \pm 0,37 \\
\pm 1,44 \\
\pm 2,04\end{array}$ & $\begin{array}{r}14 \\
6 \\
5\end{array}$ & $\begin{array}{r}+1,21 \\
+1,33 \\
-5,40\end{array}$ & $\begin{array}{l} \pm 0,43 \\
\pm 0,76 \\
\pm 3,47\end{array}$ & $\begin{array}{r}19 \\
7 \\
3\end{array}$ & $\begin{array}{r}+1,53 \\
-0,29 \\
-6,33\end{array}$ & $\begin{array}{l} \pm 0,33 \\
\pm 0,92 \\
\pm 4,33\end{array}$ \\
\hline
\end{tabular}


All three tables clearly show that hygrograms lose in accuracy according as the humidity level recorded becomes lower. At low humidity hygrographs give much too low values.

Beaumont, A.

BLEEKER, W.

BOURKe, P. M. A.

Crosier, W.

DOORN, A. M. VAN

EVERDINGEN, E. VAN

HIRST, J. M.

LivingSTON, B. E.

Penman, H. L.

Post, J. J.

— \& C. RICHEL

Stevens, N. E.

UhLIG, S.

WeILle, G. A. DE

\section{REFER EN CES}

1947 The dependence on the weather of the dates of outbreak of potato blight epidemics. Trans. Brit. mycol. Soc. 31, 45-53.

1942 Leerboek der meteorologie. II. Meten en schatten van meteorologische grootheden. Thieme \& Cie, Zutfen. $98 \mathrm{pp}$.

1955 The forecasting from weather data of potato blight and other plant diseases and pests. W.M.O. (World Meteor. Organiz.). Techn. Note No. 10, 48 pp.

1934 Studies in the biology of Phytophthora infestans (MONT.) DE BARY. Cornell Univ. Agric. Exp. Stat. Mem. No. 155, 40 pp.

1959 Onderzoekingen over het optreden en de bestrijding van valse meeldauw (Peronospora destructor) bij uien. Thesis. Wageningen 1959. Also in Tijdschr. Pl.ziekten. 65, 193-255.

1926 Het verband tussen de weersgesteldheid en de aardappelziekte (Phytophthora infestans). Tijdschr. Pl.ziekten. 32, 129-140.

1958 New methods for studying plant disease epidemics. Outlook Agric. 2, 16-26.

1917 The vapor tension deficit as an index of the moisture condition of the air. Johns Hopkins Univ. Circ. No. 293, 170-175.

1955 Humidity. Inst. Phys., Lond., Monogr. Students (Chapter I).

1957 Een nieuw onderzoek naar de samenhang tussen het weer en het optreden van aardappelziekte. Versl. eerste proefjaar (1950). K.N.M.I. (Roy. Neth. meteor. Inst.), Wet. Rapp. (57-6), 18 pp.

1959 Ditto. Versl. tweede en derde proefjaar (1957 en 1958). K.N. M.I., Wet. Rapp. (59-5), 57 pp.

1951 De mogelijkheden tot reorganisatie van de waarschuwingsdienst voor aardappelziekte. Landbk. Tijdschr. 63, 77-95.

1916 A method for studying the humidity relations of fungi in culture. Phytopathology. 6, 428-432.

1957 Untersuchungen zum Problem der Phytophthora-Warnungen. Ber. dtsch. Wetterdienst. 5 (37), 27 pp.

1963 Some remarks regarding biological observations in behalf of agrometeorological investigations concerning the epidemiology of plant diseases and pests. Arch. Meteor. Geophys. Bioklimatol., Vienna. 13, 114-136.

1964a Forecasting crop infection by the potato blight fungus. A fundamental approach to the ecology of a parasite/host relationship. Med. Verhand. K.N.M.I. No. 82 (in press).

1964b The epidemiology of plant disease as considered within the scope of agrometeorology. Agric. Meteor. 1, No. 2 (in press). 